\title{
Development of Damage Assessment Method of Rice Crop for Agricultural Insurance Using Satellite Data
}

\author{
Chiharu Hongo ${ }^{1}$, Tomonobu Tsuzawa ${ }^{2}$, Kazuhisa Tokui ${ }^{2} \&$ Eisaku Tamura $^{1}$ \\ ${ }^{1}$ Center for Environmental Remote Sensing, Chiba University, Chiba, Japan \\ ${ }^{2}$ National Agricultural Insurance Association, Tokyo, Japan \\ Correspondence: Chiharu Hongo, Center for Environmental Remote Sensing, Chiba University, 1-33 Yayoi-cho, \\ Inage-ku, Chiba, Japan. Tel: 81-43-290-3859. E-mail: hongo@faculty.chiba-u.jp
}

\author{
Received: September 6, 2015 Accepted: October 9, 2015 Online Published: November 15, 2015 \\ doi:10.5539/jas.v7n12p59 URL: http://dx.doi.org/10.5539/jas.v7n12p59
}

\begin{abstract}
Goal is to develop new method utilizing satellite data for assessment of damage in paddy field which can contribute toward substantial reduction of the damage assessment time and costs in framework of agricultural insurance. For the damage assessment, estimation of yield in each paddy plot is a key, so the research on the estimation of rice yeild was carried out using satellite data in Hokkaido, Japan. Both multiple linear regression analysis and the projection pursuit regression analysis were conducted for the estimation of yeild using data from 3 different satellites about 3 different rice varieties. As the result, the projection pursuit regression analysis showed smaller value of predictive error than that of the multiple linear regression analysis, and the lowest predictive error was indicated when SPOT5 data with $10 \mathrm{~m}$ resolution was used. Moreover, for reducing the predictive error, it was found that a yield estimation formula should be created for each of different rice varieties. The results out of this research suggest that satellite data can be effectively used for estimation of yield and also assessment of damage at lower costs to calculate indemnity in agricultural insurance.
\end{abstract}

Keywords: estimation of rice yield, satellite data, agricultural insulance, food security

\section{Introduction}

Agricultural sector including rice production is not just susceptible to loss caused by flood, drought, pest and disease attack and other meteorological events but also from the climate change. Asian agriculture is always facing with such situation (Mannava et al., 2011). Asian agriculture frequently suffers from heavy losses caused by typhoons, floods, low and high temperature and other meteorological events. Impact of the climate change is not only seen on food production, but also on food security, socio economics of the poor and sustainable development. Accordingly, adaptation to climate changes is required to minimize the risk along with the plans and strategies for food security and sustainable development.

In Japan, the agricultural insurance has been implemented for 68 years aiming to compensate farmers' losses caused by disasters, to stabilize famers' management and to contribute to development of agricultural productivity. For calculating the indemnity according to the insurance sytem, extensive and intensive loss assessment has to be conducted about all damaged areas through different assessment methods including the entire plot survey and sampling survey. One of problems relating to the assessement is that the assessment needs much labor and costs. Taking an example of the cool weather damage caused in 2003, total number of farmers who declared damages was 2.92 million; cumulative total number of the damage assessos who conducted assessment was 83,787; cumulative total number of days needed for the assessment was 173,000 days; total costs spent for the assessment was 1.1 billion yen. In addition to the costs aspect, there are some other issues to be solved which include farmers' needs for more quantitative assessment and difficulty to secure sufficient number of the assossors for the rice damage assessment. Under these problems, the situation has been guradually getting difficult to continue the conventional assessment methods, and improvement of the assessment system is now desired.

A key in agricultural insurance is the damage assessment which is required to be as precise, quick, quantitative and inexpensive as possible. As an approach to meet such requirements, introduction of innovative technologies including remote sensing technology into the insurance procedures is expected to try with high priority. The 
remote sensing technology can provide the detailed information about the damage situation covering wide area of agricultural field at one time. Since the information on damage is directly and closely related to the decision making for indemnity payment, it has to be sufficient to determine the degree of specific damage at each plot of agricultural field.

As to the remote sensing technology, development of its application has been actively tried in many areas in agricultural field. In Asian countries, rice is the staple food for the people, so research on utilization of the remote sensing technology for rice production and paddy field management has been conducted on various subjects such as yield estimation, soil improvement and irrigation.

As an example of such research works, development of the algorithms for rice field mapping and production estimation was conducted (Xiao et al., 2005; Takezawa et al., 2007; Shikata et al., 2013). And there are many reports already available introducing the analysis results using MODIS data which has low resolution but can be acquired with high frequency. For example, extraction of paddy fields in Southeast Asia was made on basis of change of phenology of rice and the mapping was prepared with $80 \%$ accuracy (Gumma et al., 2011). In order to estimate yield of rice, at first, extraction of paddy field where rice is planted has to be conducted using satellite data. In Southeast Asia, rice is planted and harvested 2 to 3 times a year, so MODIS data is often used because it can be acquired with high frequency. According to the report of Peng et al. (2011), the pixels representing paddy fields with early ripening rice and the pixels with slow ripening rice could be separated with use of both MODIS data and SPOT data having high resolution. In the report of Yuei-An et al. (2012), analysis was made about the paddy field damaged by the catastrophic earthquake and tsunami hit occurred in the northeastern part of Japan on March 11, 2011 with the result that decrease in rice yield per year in Miyagi Prefecture was estimated as 9,472 ton using MODIS data and the rice yield estimate (RICE) algorithm.

As other approach to the estimation of yield, there are some research works up to now where some models are used. As an example of such research, Mirco et al. (2011) reported about the use of Lifht Use Efficiency model for rice estimation where MODIS data was used as a parameter of fPAR in the model. According to the result, RMSE calculated by the model was $15-17 \%$ in comparison with the production statistics reported by government. Another example is a case where the remote sensing data is incorporated into a crop model. In this case, LAI, one of important predictors for estimation of rice yield, was calculated using TIPS (Time-series change Index of Plant Structure) and it was suggested that it could be effective for estimating rice yield covering wide area (Oki et al., 2013; Maki et al., 2014). However, there are very few reports introducing rice yield estimation of each individual paddy plot using satellite data in areas having small size of paddy field in Asian countries. We conducted research on estimation of rice yield in small paddy plots on individual basis in Indonesia during dry season using shortwave infrared band and NDVI derived from SPOT 5 data. The result showed that the error was about 0.77 ton/ha (Hongo et al., 2014).

In recent years, the weather index insurance has been tried in some countries in Africa and Southeast Asia, and the gap between the actual damage and the evaluation result through index scheme has been pointed out as a serious issue to be solved. As one of possible solutions, use of NDVI value or other information to be derived from remote sensing data is expected to be an effective solution to the gap issue (The World Bank, 2011; Jan et al., 2014).

In case of the weather index insurance, the area to be evaluated is not 'each individual plot' but rather wide area. In the Japanese agricultural insurance scheme, damage is evaluated on each individual plot and the indemnity is calculated and paid according to the assessment result of each individual plot damaged. However, there was no report introducing the use of remote sensing data for estimation of yield on each individual plot basis which shall be a base for assessment of damage of paddy fields.

So, in this research, the final goal is to integrate satellite data into the damage assessment system for rice and also to implement the integrated system in Asia. Having this goal, in order to make and improve the damage assessment process more effectively, the yield estimation of different rice varieties on each individual plot was conducted using a few different satellite data with different resolution levels and also 2 different statistical models. Then, comparison of estimation accuracy was made betweem the different models, different satellite data and different rice varieties.

\section{Outline of Japanese Agricultural Insulance Scheme}

The agricultural insulance scheme of Japan was established in 1947. The evaluation procedure of the damage assessement of rice crop is shown in Figure 1. This is Government support sytem to farmers' mutual relief. According to the scheme, three-tier organization is set up consisting of municipal level, prefectural level and national level. At the municipal level, Agricultural Mutual Relief Association (AMR) collects premiums from 
farmers and pays indeminities to farmers. Prefectural Federation of AMRs, as the prefectural level, shares a part of insulance liability with AMRs. The national level is the Ministry of Agriculture, Forestry and Fisheries of Japan (MAFF) which shares a part of liability with the prefectural federation of AMRs. There are 235AMRs and 38 prefectural federations of AMRs in Japan as of January 1, 2014. MAFF guides and supervises the AMR and the prefectural federation of AMR, and it holds the agricultural re-reisurance special accout. MAFF shares about a halr of the premium with farmers.

In the procedure, several different damage evaluation works are conducted. At the municipal level, estimation by eyes and a sampling survey are conducted and at the level of the federation a sampleing survey is conducted separately from the survey to be done by AMR. Among the evaluation works at different levels, the damage evaluation by AMR is the most time and cost consuming step. So, our study aims at development of a new damage assessment method using satellite data to save time and cost of the evaluation at level of the AMR.

In addition to the needs for time and cost saving, some more items are listed up as specific and important needs for improvement which are more quantitative and quicker evaluation covering wider area. These needs are expected to be satisfied through development of new methods.

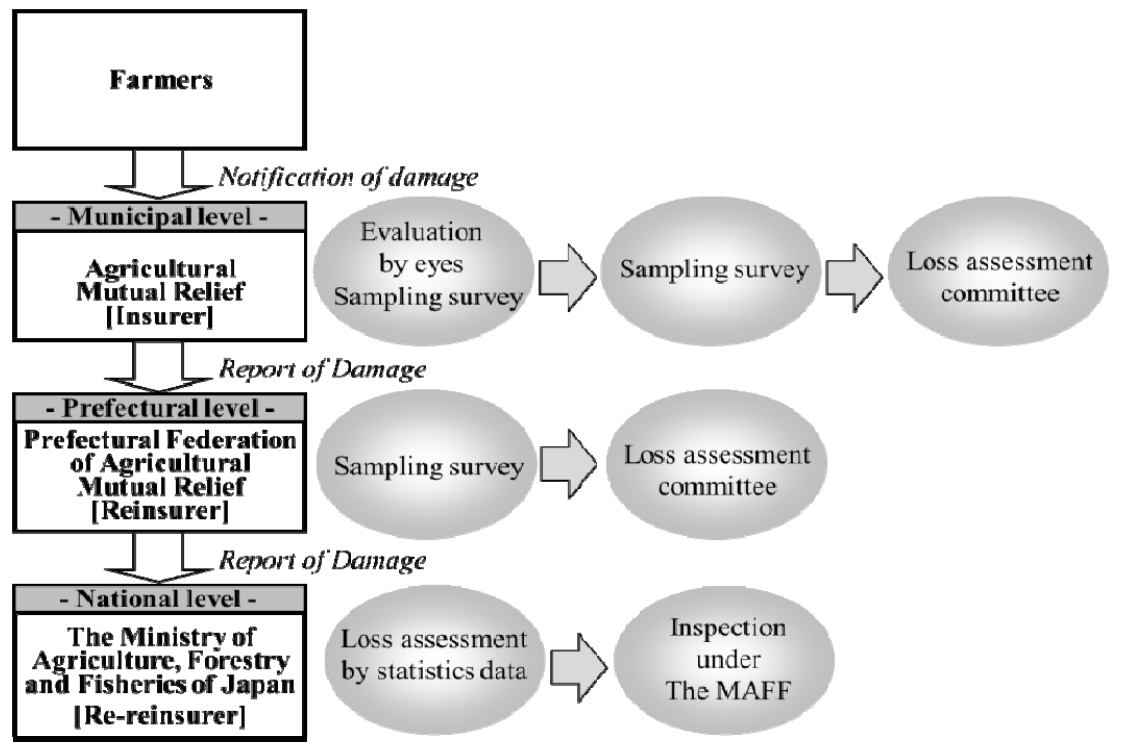

Figure 1. Evaluation procedure of damage ratio

\section{Study Site}

Study site in this research is located in the central part of Hokkaido which is a famous rice production area in Japan. The total area of rice field in the study site is about 4,000 hectares, and the average cultivation area per individual paddy plot is 33 ares (Figure 2).

The study site has, since located in a basin, the inland climate and a significant temperature difference between summer and winter, and in winter season all agricultural land is completely covered with snow.

The altitude of the site ranges from $120 \mathrm{~m}$ to $150 \mathrm{~m}$ and geographical type of paddy field is lowland of which soil type is the alluvial deposit according to the soil classification of FAO. 


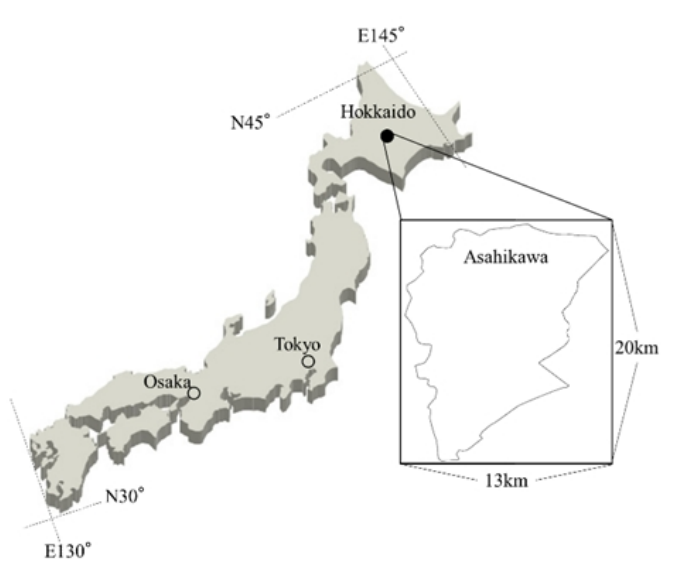

Figure 2. Study site

\section{Materials and Methods}

\subsection{Data for Analysis}

\subsubsection{Production Data of Rice}

In this research, in order to get the ground truth data, a group of National Agricultural Insurance Association (NOSAI) conducted the survey on both September 19 and 20 in 2007. Figure 3 shows an outline of the surevey method which is a formal survey method designated by MAFF for evaluation of damage of paddy fields. According to the method, at first, 6 different points in one plot of paddy are set up as is shown in the figure. At each point, 10 hills of rice plant are harvested and weight of the unhulled rice is measured. Finally the weight is converted to yield per 10 ares through consideration of rice plant density of the plot.

For this research, 3 different varieties of rice crop were selected. Names of the selected varieties and number of paddy plots where each of the varieties is planted are as follows: Kirara 397 in 189 plots, Hoshinoyume in 145 plots and Nanatsuboshi in 69 plots.

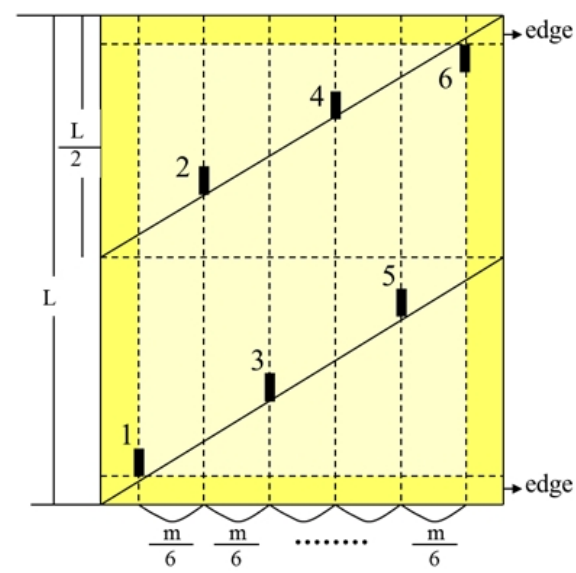

Figure 3. Illustration of sampling points in a plot

Note. m: number of ridge; L: length of paddy plot; m/6: Interval of sampling; 1, 2, 3, 4, 5, 6: position of sampling.

\subsubsection{Satellite Data and GIS Data}

In this study, in order to compare the estimated values of rice yield, three different satellites were selected and data from these satellites were used for analysis. Names of the each satellite and date when the satellite data was obtained are as follows: (1) ALOS/AVNIR-2 satellite having 4 bands as observation wavelength of blue band 
$(420-500 \mathrm{~nm})$, green band $(520-600 \mathrm{~nm})$, red band $(610-690 \mathrm{~nm})$, near infrared band $(760-890 \mathrm{~nm})$ with $10 \mathrm{~m}$ image resolution, and the date was on September 18, 2007, (2) SPOT 5 satellite (HRG-X) and the date was on September 1, 2007, and (3) SPOT 4 satellite (HRVIR-X) and the date was on September 18, 2007. Both SPOT 5 and SPOT 4 satellites have 4 bands: green band $(500-590 \mathrm{~nm})$, red band $(610-680 \mathrm{~nm})$, near infrared band $(780-890 \mathrm{~nm})$ and short-wavelength infrared band $(1580-1750 \mathrm{~nm})$. Concerning the image resolution, SPOT 5 has $10 \mathrm{~m}$ resolution for the visible bands and near-infrared band and $20 \mathrm{~m}$ resolution for short-wavelength infrared band while SPOT 4 has $20 \mathrm{~m}$ resolution of the bands.

GIS data of 2007 for the study was provided by Soil Improvement Organization in Hokkaido to identify and extract paddy fields from the satellite data. Figure 4 shows the SPOT5 data with GIS data of the paddy fields. GIS data has following attributes: standard yield, type of damages, varieties of rice cultivated, name of farmer, etc. The standard yield means an average of yield/10a of the past 5 years at each plot of paddy field, where the 5 years are selected in the past 7 years excluding the year with the maximum yield and the year with minimum yield.

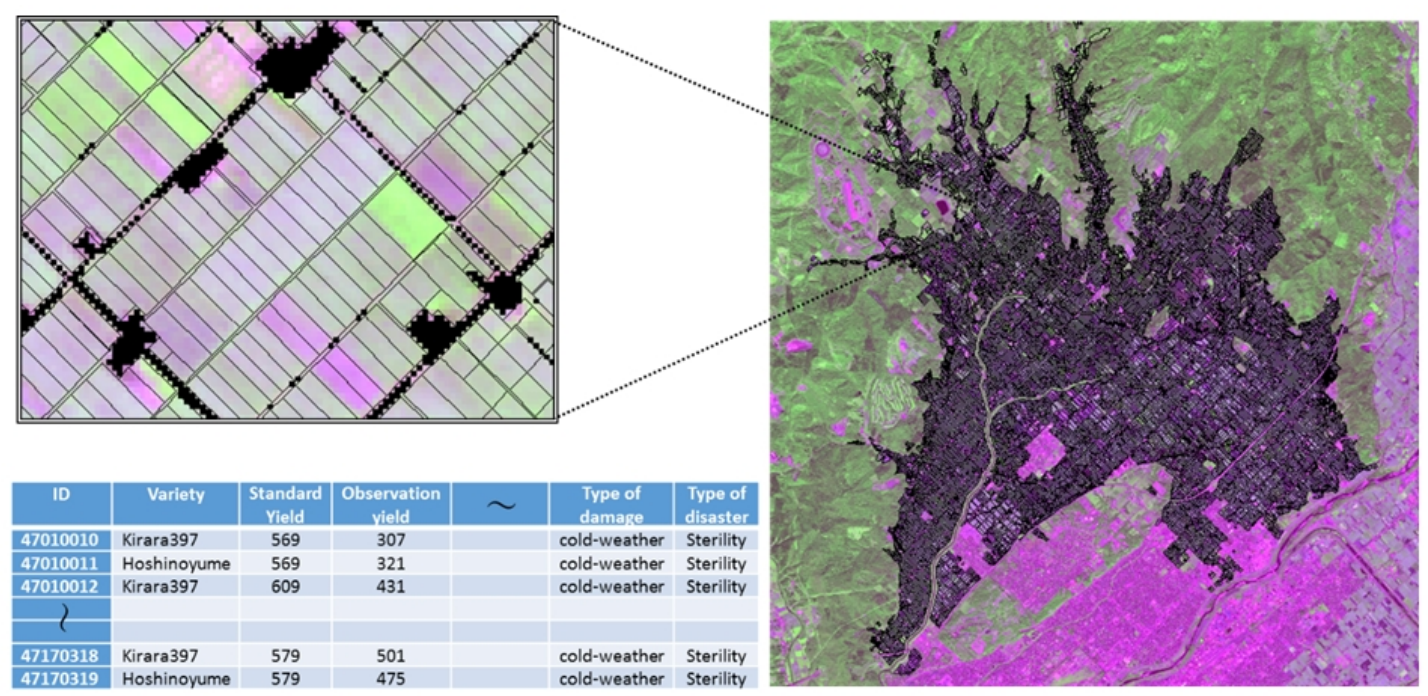

Figure 4. SPOT5 data with GIS data of paddy fields

\subsection{Procedure of Rice Yield Estimation}

Figure 5 shows analysis procedure for rice yield estimation. At first, 3 different satellite data were rectified by nearest neighbor resampling algorithm with use of the data on the ground control points; a shape file of paddy fields was prepared based on GIS data and was overlaid on the satellite data; then paddy fields were extracted. After this step, digital values in the paddy fields were picked up; 2 different statistical models, which are multiple linear regression analysis and projection pursuit regression model, were used for estimation of rice yield; NDVI and GNDVI were also calculated.

Definition of NDVI and GNDVI are as follows:

$$
\begin{aligned}
& \text { NDVI: Normalized Difference Vegetation Index }=(\mathrm{NIR}-\mathrm{R}) /(\mathrm{NIR}+\mathrm{R}) \\
& \text { GNDVI: Green Normalized Difference Vegetation Index }=(\mathrm{NIR}-\mathrm{G}) /(\mathrm{NIR}+\mathrm{G})
\end{aligned}
$$

Where, $\mathrm{G}$ is visible green radiation, $\mathrm{R}$ is visible red radiation and NIR is near infrared radiation.

Finally, 10-fold cross-validation by random data partitioning was conducted to compare the prediction errors about cases using each of different models and different satellite data. 


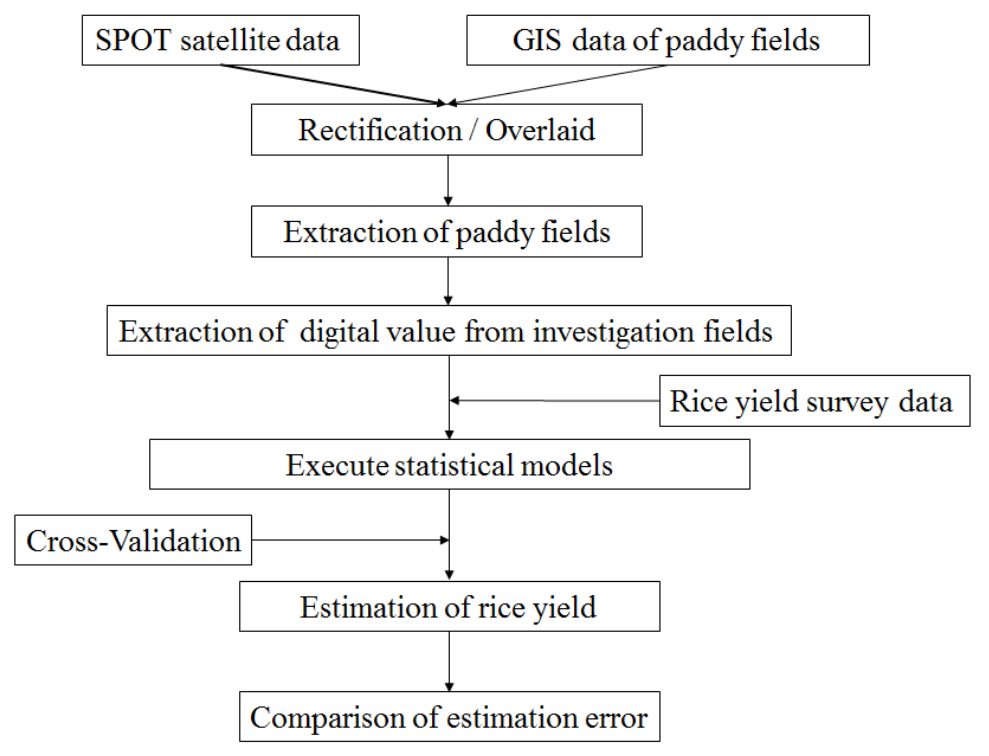

Figure 5. Procedure of analysis

\subsection{Statistical Model}

\subsubsection{Multiple Linear Regression Analysis}

Multiple linear regression analysis is a technique to estimate a target variable using two or more explanatory variables. The following model gives the regression equation:

$$
y_{i}=a_{0}+\sum_{j=1}^{p} a_{j} x_{j}
$$

Where, $y$ : target variable, $x$ : explanatory variable; $a$ : regression coefficient, $p$ : number of explanatory variable; data: $x_{i}(1 \leq i \leq \mathrm{n}, 1 \leq j \leq \mathrm{n})$.

\subsubsection{Projection Pursuit Regression Model}

The projection pursuit regression yields the regression equation:

$$
f\left(x_{1}, x_{2}, \ldots, x_{r}\right)=a_{0}+\sum_{j=1}^{M} S_{j}\left(\sum_{k=1}^{r} a_{k j} x_{k}\right)
$$

Where, $\left\{S_{j}\left(x_{1}, x_{2}, \ldots x_{r}\right)\right\}$ are regression equations. These regression equations are constructed by smoothers, which are based on a nonparametric regression technique, so that smoothing yield appropriately smooth equations.

$\left\{x_{1}, x_{2}, \ldots x_{r}\right\}$ are predictors. $\alpha_{0}$ is the regression coefficient. $\left\{S_{j}\right\}(1 \leq j \leq \mathrm{M})$ are nonparametric functions. $\left\{\alpha_{k j}\right\}(1$ $\leq j \leq \mathrm{M}, 1 \leq k \leq r)$ are regression coefficients for reflecting predictors.

\section{Results and Discussion}

\subsection{Comparison of Statistical Model to Estimate Rice Yield}

The multiple regression analysis was conducted for estimation of rice yield in the harvesting season with use of the following: values on green band (S5-G, S4-G), red band (S5-R, S4-R), near infrared band (S5-NIR, S4-NIR), short-wavelength infrared band (S5-SWIR, S4-SWIR) and values on NDVI and GNDVI calculated from SPOT5 and SPOT4 satellite data. As the result, for SPOT 5, following were selected as the predictors: values on green, near infrared, short-wavelength infrared and GNDVI, while green, near infrared, short-wavelength were selected for SPOT 4. For case of ALOS, blue, red, near infrared and GNDVI became the predictors.

According to the report of Aboelghar et al. (2011), high correlation was obtained between the yield of rice and the predictors including visible bands, near infrared band and vegetation indices derived from SPOT data. The results developed in this research show high similarity to the report.

Following are estimation formulas which were created in this research:

$>$ Estimation formula using SPOT 5 data

$\mathrm{y}=50.09(\mathrm{~S} 5-\mathrm{G})$ - $47.07(\mathrm{~S} 5-\mathrm{NIR})$ - 2.61 (S5-SWIR) + 13918.35 GNDVI - $95.91(\mathrm{r}=0.57, \mathrm{p}<0.05)$ 
$>\quad$ Estimation formula using SPOT 4 data

$\mathrm{y}=-5.30(\mathrm{~S} 4-\mathrm{G})+3.24(\mathrm{~S} 4-\mathrm{NIR})-0.94(\mathrm{~S} 4-\mathrm{SWIR})+516.73(\mathrm{r}=0.34, \mathrm{p}<0.05)$

$>$ Estimation formula using ALOS data

$\mathrm{y}=-12.58(\mathrm{~A}-\mathrm{B})-54.58(\mathrm{~A}-\mathrm{R})-30.14(\mathrm{~A}-\mathrm{NIR})+7215.61$ GNDVI $-819.08(\mathrm{r}=0.57, \mathrm{p}<0.05)$

Then, the projection pursuit regression model was tried for estimation of yield and following results were obtained: $(\mathrm{r}=0.70, \mathrm{p}<0.01)$ for SPOT 5 data, $(\mathrm{r}=0.60, \mathrm{p}<0.01)$ for SPOT $4,(\mathrm{r}=0.57, \mathrm{p}<0.05)$ for ALOS data. These data mean that high correlation can be seen between the model and the yield whichever satellite data is used.

Total 731 paddy plots having 3 different rice varieties were devided into 10 groups. The 10 -fold cross-validation by random data partitioning was applied for estimation of predictive errors. Figure 6 shows the results calculated through the 10-fold cross-validation about cases using 2 models. The prediction error calculated was $49.1 \mathrm{~kg} / 10 \mathrm{a}$ for SPOT5, $55.4 \mathrm{~kg} / 10$ a for ALOS and $56.5 \mathrm{~kg} / 10$ a for SPOT4 against the actual yield. When the projection pursuit regression model was conducted with use of the same predictors, the prediction error was $43.7 \mathrm{~kg} / 10 \mathrm{a}$ for SPOT5, $48.3 \mathrm{~kg} / 10$ a for SPOT4 and $49.2 \mathrm{~kg} / 10$ a for ALOS data.

The projection pursuit regression model is considered to be an effective method to make the smoothing through nonparametric regression using all predictive variables. The above result indicates that the projection pursuit regression model shows lower values of the predictive error in comparison with the multiple regression analysis when larger number of sample is available. In addition, in case of using the projection pursuit regression, the error was smaller when satellite data with higher resolution was used. There sometimes happens a case where a pixel contains reflection value of other pixel adjacent to the pixel. For example, a pixel near boundary of paddy plot contains information on such as ridge between the plots and also other neiboring plot. In this research, in order to reduce influence of this mixel, boundary of plot was moved toward $10 \mathrm{~m}$ inside on GIS field, and then digital value was extracted. However, in case of SPOT 4, since the resolution is $20 \mathrm{~m}$, it was difficult to reduce the mixel influence completely with the result that the estimation error became relatively bigger.

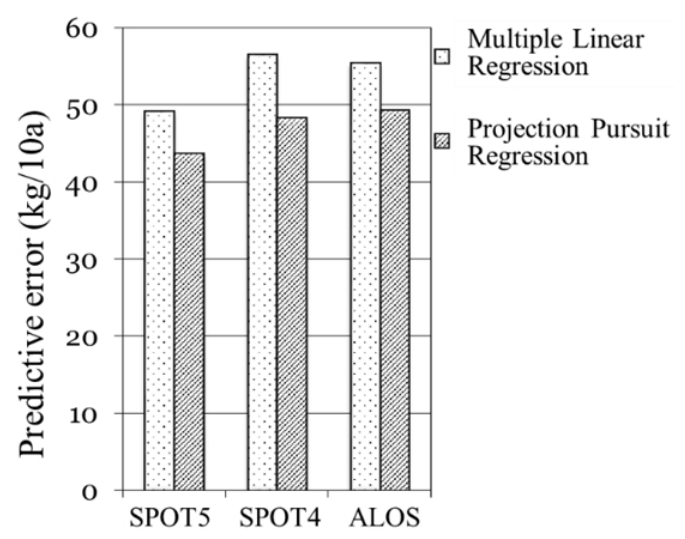

Figure 6. Predictive error of each regression model

\subsection{Comparison of Prediction Error of Each Variety}

Analysis of all paddy plots having 3 different rice varieties was made with the result that the projection pursuit regression model gave smaller prediction error than that calculated by the multiple regression analysis. So, using the projection pursuit regression model, estimation of rice yield was conducted on each of the rice varieties, expecting to improve the error. The results of the estimation on all varieties and each of the varieties are shown in Figure 7. The predictive error becomes smaller in the following order:

$>$ SPOT5: Hoshinoyume $(26.1 \mathrm{~kg} / 10 \mathrm{a})>\operatorname{Kirara397}(25.6 \mathrm{~kg} / 10 \mathrm{a})>$ Nanatsuboshi $(9.1 \mathrm{~kg} / 10 \mathrm{a})$

$>$ SPOT4: Kirara397 (35.7 kg/10 a) > Hoshinoyume (32.3 kg/10 a) > Nanatsuboshi $(13.2 \mathrm{~kg} / 10 \mathrm{a})$

$>$ ALOS: Hoshinoyume (35.6 kg/10 a) > Kirara397 (29.1 kg/10 a) > Nanatsuboshi (10.3 kg/10 a) 


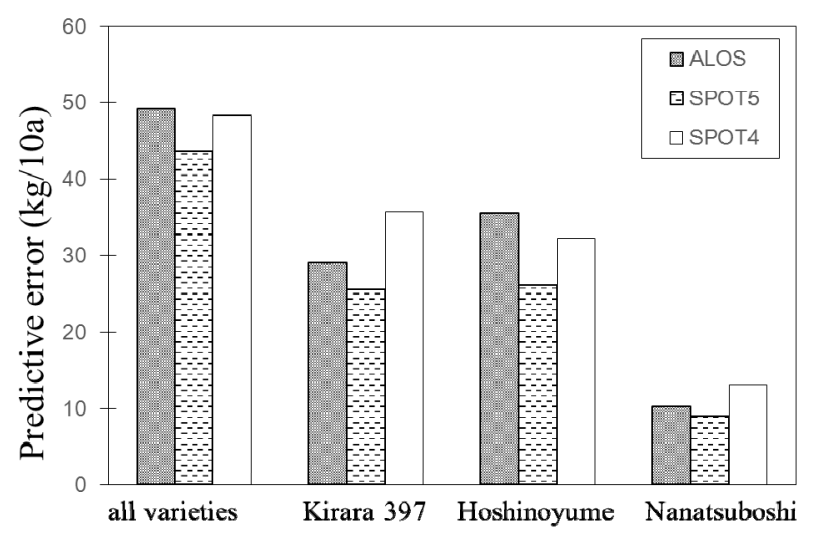

Figure 7. Predictive error of each variety

An average of the predictive errors calculated on each variety using 3 different satellite data was $31.3 \mathrm{~kg} / 10$ a for hoshinoyume, $30.1 \mathrm{~kg} / 10$ a for Kirara 397 and $10.8 \mathrm{~kg} / 10$ a for Nanatsuboshi respectively.

The predictive error calculated from SPOT 5 data (Figure 8) was smaller than the value from ALOS data (Figure 9). As is mentioned above, ALOS satellite has visible and near infrared sensors while SPOT 5 has, in addition to these sensors, sensor for short-wavelength. The result indicated that the increasing of the reflectance data and the data with short-wavelength band could be effective to improve the prediction error.

The prediction error from SPOT 5 data was smaller than that from SPOT 4 data as is shown in Figure 10. Difference in the image resolution between SPOT 5 and SPOT 4 is considered to be a reason why the predictive error was smaller in case of using SPOT 5 data than that in case of SPOT 4.

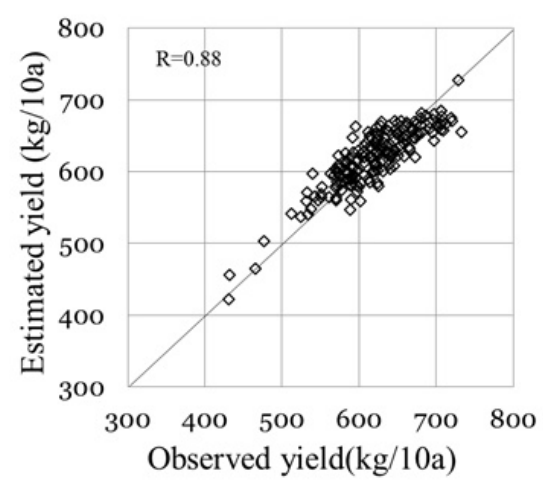

Figure 8. Relationship between estimated yield and observed yield of SPOT 5 data

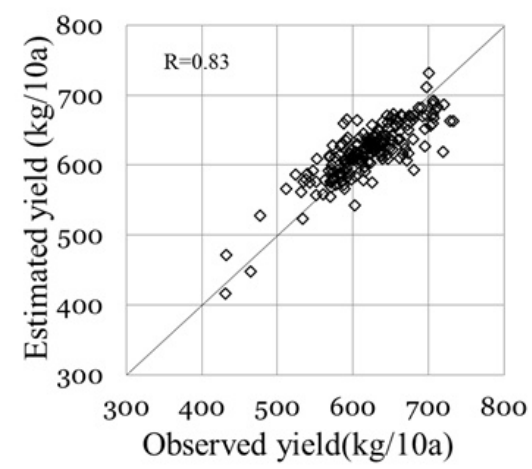

Figure 9. Relationship between estimated yield and observed yield of ALOS data 


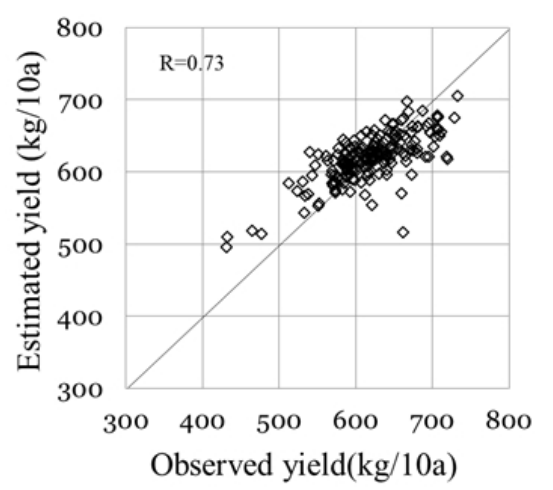

Figure 10. Relationship between estimated yield and observed yield of SPOT 4 data

\begin{abstract}
Abbasi et al. (2011) made analysis of red edge through measurement of spectral reflection about 7 different varieties with the result that it was confirmed that the position of red edge moved according to a type of varieties. In this research, average of digital value of predictor on each variety was compared; then it was suggested that there was a difference in the average value of red, near infrared and NDVI and also 5\% level of significant difference was found for near infrared and NDVI. Concerning a strain of the varieties, the first generation of Kirara 397 is Hoshinoyume and the second generation of Kirara 397 is Nanatsuboshi. These 3 varieties appear quite similar to each other in terms of height of plant, number of head, color and etc. However, when compared with Hoshinoyume and Nanatsuboshi, Kirara 397 is relatively easy to fall down and week against rice blast which are week points. This means that when rice blast occurs, situation of disease occurrence may appear different depending on what varieties are planted and in which paddy field. And, although there is almost no difference in height and biomass volume of the varieties, number of unhulled rice in one head is different: Hoshinoyume and Nanatsuboshi have bigger number than that of Kirara 397. This means that accuracy of yield estimation can be improved by separating each variety at time of planting.
\end{abstract}

\title{
4.3 Ratio of Estimated Yield to Standard Yield
}

Result of the yield estimation obtained from SPOT 5 data was visualized as a map which is shown in Figure 11. Then, in the map, we extracted all the paddy field for which farmers had submitted the notification of damage caused by rice blast to AMR. About the extracted paddy field, ratio of the estimated yield to the standard yield was calculated. Finally, the calculation result was visualized which is shown in Figure 12. Blue colored part shows $10 \%$ decrease, yellow parts $10-40 \%$ and red parts $40 \%$ or more. In this paper, from viepoint of privacy protection, any specific information relating to the calculation resuls on indemnity can't be disclosed, however, in actual operation of the insurance, indemnity can be calculated through input of the decrease ratio into the calculation formula about each of damaged paddy plots and, based on the calculation result, the indemnity can be paid according to the coverage of the insurance which each farmer decides at time of the contract.

At time of implementation of the damage assessment using satellite data, the cost would be one of issues to be solved. Shao et al. (2011) tried to estimate rice yield in China with use of crop model and multi-temporal RADASAT. In this case, satellite data was needed at least 3 times a year, which would be a problem in terms of costs when the damage assessement with this method is implemented.

In this research, the cost of SPOT5 image was about 130 yen per hectare. In 2003, Japan had the worst damage in the past 25 years. For assessment of the damage, it was reported that total 1.1 billion yen was spent as labor costs for the damage assessors and the paddy area assessed by each damage assessor was about $4.8 \mathrm{ha}$ and its labor cost was about 13,000yen. If the satellite data should have been used, the assessment cost would be about 624 yen to cover the same area. This means that the assessment method utilizing satellite data and GIS data for calculation of damage could contribute a lot to realize substantial cost saving for case of great damage like the case of 2003. Our results will contribute to saving of the cost for the damage assessment at level of the Agricultural Mutual Relief Association. In the study site, actual operation of the damage assessment system using satellite data and GIS data started in 2013. And now, in other prefectures, the implementation of this system is under serious consideration. 


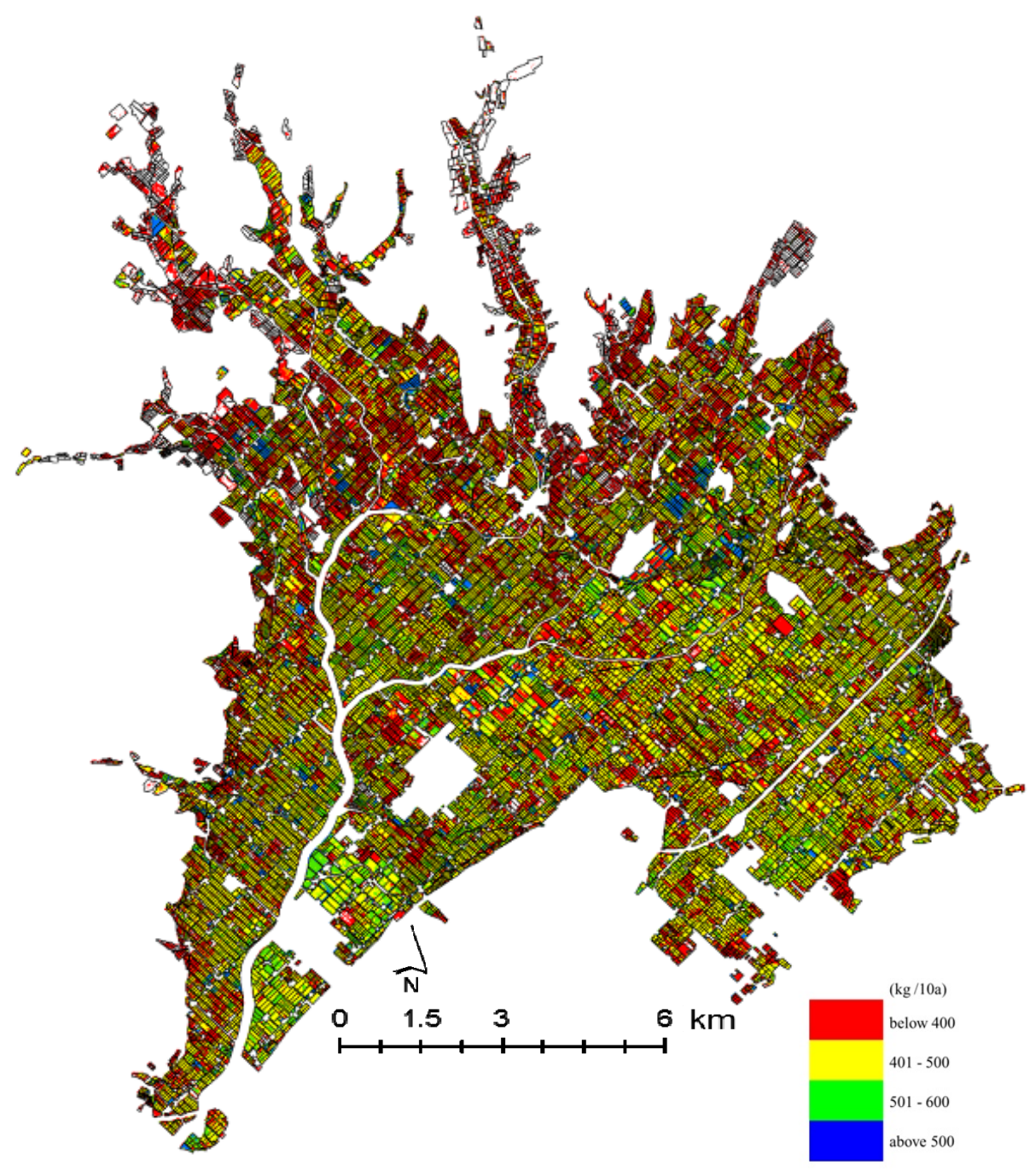

Figure 11. Map of rice yield 

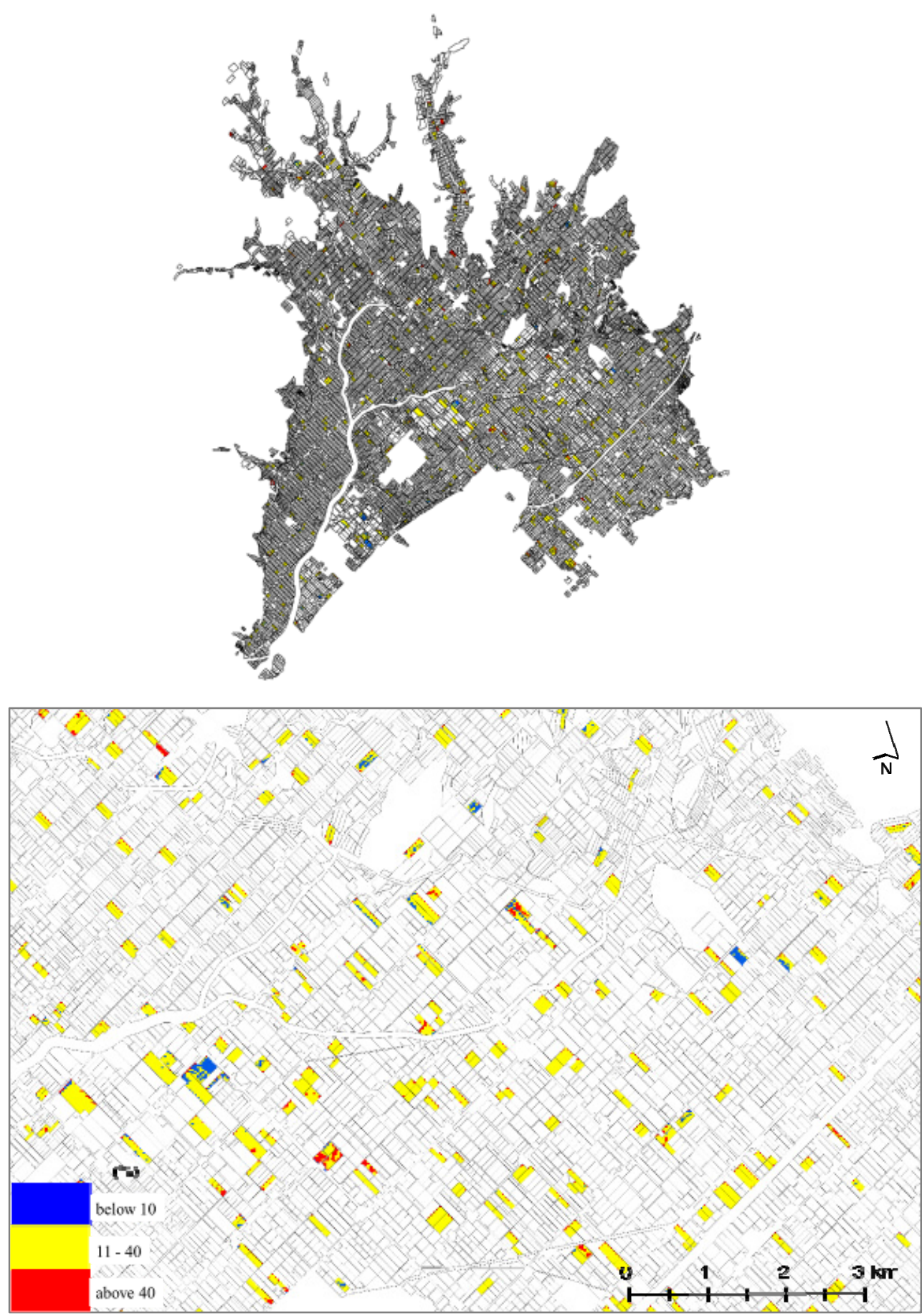

Figure 12. Map of ratio of estimated yield against standard yield

\section{Summary}

The goal of this research is to integrate satellite date into damage assessment system for rice crop and to implement the new assessment method in the future. With this goal, in order to improve effectiveness of the damage assessment to be conducted in the agricultural insurance scheme, estimation of rice yield was conducted using satellite data of SPOT 5, SPOT 4 and ALOS/AVNIR2 and also 2 different statistical models; then accuracy of the estimation was compared.

The projection pursuit regression model can give the estimation result with lower predictive error at about $10 \%$ than the case of applying the multiple regression analysis. Like case of this research where number of sample is sufficient, the projection pursuit regression model is suggested to be more effective because it can better handle 
multivariate data.

Using the projection pursuit regression model, estimation error was calculated about damaged paddy fileds and each varietiy; then comparison was made among the errors. As the result, the error was smaller for a case where each estimation formula was created about damaged paddy fileds and each varietiy than a case where an estimation formula was generated covering all paddy fields.

Use of the remote sensing data and models could help us estimate the rice yield quantitatively covering wide paddy field in advance to the harvesting. When the satellite data is utilized for the assessment of damage in the agricultural insurance framework, it can realize reduction of time and costs substantially. In addition to the reduction aspect, more quantitative and quicker assensement covering wider paddy field could be expected. Actually in Japan, the new damage assessment system using satellite data is in operation now.

Finally, agriculture is a key industry for every country and the agricultural insurance is one of key social infrastructures to protect agriculture as adaptation to climate change for food security. In order to improve the insurance system and also to promote dissemination of the insurance, the remote sensing technology and spatial information could make much contribution in the future.

\section{References}

Abbasi, M., Darvishsefat, A. A., \& Schaepman, M. E. (2010). Spectral Reflectance of Rice Canopy and Red edge Position (REP) as Indicator of High-yielding Variety. ISPRS TC VII Symposium (Vol. XXXVIII, Part 7B).

Aboelghar, M., Arafat, S., Abo Yousef, M., El-Shirbeny, M., Naeem, S., Massoud, A., \& Saleh, N. (2011). Using SPOT data and leaf area index for rice yield estimation in Egyptian Nile delta. The Egyptian Journal of Remote Sensing and Space Sciences, 14, 81-89. http://dx.doi.org/10.1016/j.ejrs.2011.09.002

Chiharu, H., Gunardi, S., Ryohei, S., Katsuhisa, N., \& Eisaku, T. (2014). The Use of Remotely Sensed Data for Estimating of Rice Yield Considering Soil Characteristics. Journal of Agricultural Science, 6(7), 172-184. http://dx.doi.org/10.5539/jas.v6n7p172

Gumma, M. K., Nelson, A., Thenkabail, P. S., \& Singh, A. N. (2011). Mapping rice areas of South Asia using MODIS multitemporal data. Journal of Applied Remote Sensing, 5(1). http://dx.doi.org/10.1117/1.3619838

Jan, de L., Anton, V., Apurba, S., Clement, A., Kiros, M. H., Chandrashekhar, M. B., ... Calum, T. (2014). The Potential and Uptake of Remote Sensing in Insurance: A Review. Remote Sens, 6, 10888-10912. http://dx.doi.org/10.3390/rs61110888

Kazuo, O., Keigo, N., Koshi, Y., Issaku, A., Masayasu, M., Koki, H., ... Hiroaki, S. (2013). Development of an Environmentally Advanced Basin Model in Asia. Crop Production. InTech. http://dx.doi.org/10.5772/46177

Mannava V. K. S., \& Robert, S. (2011). Climate Change and Food Security in South Asia. Springer Science + Business Media B. V. http://dx.doi.org/10.1007/978-90-481-9516-9_2

Masayasu, M., \& Koki, H. (2014). Empirical Regression Models for Estimating Multiyear Leaf Area Index of Rice from Several Vegetation Indices at the Field Scale. Remote Sens, 6, 4764-4779. http://dx.doi.org/10.3390/rs6064764

Mirco, B., Daniela, S., Roberto, C., Pietro, A. B., Alberto, C., \& Stefano, B. (2011). Estimation of rice production at regional scale with a Light Use Efficiency model and MODIS time series. Italian Journal of Remote Sensing, 43(3), 63-81. http://dx.doi.org/10.5721/ItJRS20114335

Peng, D. L., Huete, A. R., Huang, J. F., Wang, F. M., \& Sun, H. S. (2011). Detection and estimation of mixed paddy rice cropping patterns with MODIS data. International Journal of Applied Earth Observation and Geoinformation, 13(1), 13-23. http://dx.doi.org/10.1016/j.jag.2010.06.001

Ryohei, S., Chiharu, H., \& Gunardi, S. (2013). Analysis of relationship between the estimated rice yield and the irrigation water system in West Java. Proceedings of the International Symposium on Remote Sensing (pp. 303-306).

Takezawa, K., Subbaiya, R. K., Seish, N., Chiharu, H., Kazuhisa, T., Akihiko, I., \& Toshiaki, T. (2007). Preliminary report on regression equations based on remote sensing data to estimate rice yield. Journal of Japanese Agricultural Systems Society, 23(2), 177-187.

The World Bank. (2011). Weather Index Insurance for Agriculture. Retrieved from http://www.agriskmanagementforum.org/sites/agriskmanagementforum.org/files/WEATHER\%20INDEX\% 20INSURANCE\%20FOR\%20AGRICULTURE_WB_WII_Paper_Nov_2011.pdf 
Xiao, X., Boles, S., Liu, J., Zhuang, D., Frolking, S., Li, C., \& Moore, B. (2005). Mapping paddy rice agriculture in southern China using multi-temporal MODIS images. Remote Sensing of Environment, 95(4), 480-492. http://dx.doi.org/10.1016/j.rse.2004.12.009

Yuei-An, L., Hsueh-Chun, S., Ting-Ming, C., Tai-Sheng, W., Yi-Ting, L., Yen-Cheng, L., ... Li-The, L. (2012). Assessment of Disaster Losses in Rice Paddy Field and Yield after Tsunami Induced by the 2011 Great East Japan Earthquake. Journal of Marine Science and Technology, 20(6), 618-623. http://dx.doi.org/10.6119/JMST-012-0328-2

Yun, S., Xiangtao, F., Hao, L., Jianhua, X., Ross, S., Brisco, B., ... Staples, G. (2001). Rice monitoring and production estimation using multitemporal RADASAT. Remote Sensing of Environment, 76, 310-325. http://dx.doi.org/10.1016/S0034-4257(00)00212-1

\section{Copyrights}

Copyright for this article is retained by the author(s), with first publication rights granted to the journal.

This is an open-access article distributed under the terms and conditions of the Creative Commons Attribution license (http://creativecommons.org/licenses/by/3.0/). 